\title{
Automatic Accompaniment to Arab Vocal Improvisation: From Technical to Commercial Perspectives
}

\author{
Fadi M. Al-Ghawanmeh1, Zaid R. Shannak² \\ ${ }^{1}$ Music Department, University of Jordan, Amman, Jordan \\ ${ }^{2}$ SRS International, Amman, Jordan \\ Email: f ghawanmeh@ju.edu.jo, zaid.shannak@gmail.com
}

Received 11 November 2014; revised 28 December 2014; accepted 12 January 2015

Copyright (C) 2015 by authors and Scientific Research Publishing Inc.

This work is licensed under the Creative Commons Attribution International License (CC BY). http://creativecommons.org/licenses/by/4.0/

\section{(c) (i) Open Access}

\begin{abstract}
In this multidisciplinary study, the main research question was how to improve the value of entrepreneurial initiatives that provide the web service of automatic accompaniment to Arab singing. As an example and case study, we considered the Mawaweel website that offered an automatic accompaniment to Arab vocal improvisation as a main service. After overviewing the website, we conducted a survey examining the satisfaction of its visitors in regard to presentation and quality of service. It was found that the Mawaweel website had potential to achieve success as the majority of the 22 respondents expressed general satisfaction after their first visit to the website, with an average rate of $\mathbf{7 5 \%}$. However, respondents' ratings were strict when discussing specific aspects about the website presentation and service quality, and the means of average rates were $68.32 \%$ and $50.23 \%$ respectively. The standard deviations of average rates were $15.70 \%$ and $19.13 \%$, respectively. This revealed a sense of inhomogeneity in the values of the different aspects of the website presentation, and an expanded sense of inhomogeneity in the quality of the different services delivered by the website. We then compared the Mawaweel website to other websites and proposed specific improvements to the aspects with average rate below $50 \%$.
\end{abstract}

\section{Keywords}

Music Informatics, Entrepreneurial Web Business, Automatic Accompaniment, Arab Music, Survey Research

\section{Introduction}

The population of the Arab region, occupying most of the Middle East and North Africa, is growing rapidly.

How to cite this paper: Al-Ghawanmeh, F.M. and Shannak, Z.R. (2015) Automatic Accompaniment to Arab Vocal Improvisation: From Technical to Commercial Perspectives. Journal of Software Engineering and Applications, 8, 16-25. 
According to [1], this should imperatively be accompanied by a powerful economic growth as the population will double to reach 800 million by 2050. The reference also added that the arrival of new technologies, the opening up of Arab economies, and the capital yielded by oil investments are all factors encouraged the development of small and medium enterprises in the Arab region.

The Arab world internet population is growing much faster. According to [2] and as shown in Table 1, the number of internet users grew from 20 million to 77 million in the Middle East and from 34 to 140 million in Africa with growth rates of $285 \%$ and $311 \%$, respectively. This far exceeds the worldwide growth rate, which is $96 \%$. These statistics affirm the competence of the web as a promising investment venue for the Arab world.

The growth of the media and entertainment sector in the Arab world is also impressive. According to [3] and as depicted in Figure 1, the spending on media and entertainment doubled between 2003 and 2007 to reach \$10 billion with a compound annual growth rate of $19 \%$. The figure also shows that the total investment in the Arab region is still far below the numbers reported in different parts of the world such as China or Germany where the total investments are $\$ 74$ billion and $\$ 111$ billion, respectively. This means that the Arab region has a huge potential for further growth in this promising industry. All the above-presented statistics affirm the significance of this study as we aim at improving the commercial value of an entrepreneurial web-based entertainment initiative that is targeted at the Arab people.

In this multidisciplinary article, we aimed at increasing the traffic and the commercial significance of the Mawaweelwebsite [4], as an example of sites offering the service of automatic musical accompaniment to Arab singing. As we considered the survey research as an efficient model for measuring costumers' satisfaction and for obtaining their feedback, we overviewed the Mawaweel website, and then we prepared and disseminated a survey to a sample of potential users. The survey assessed the users' level of satisfaction, mainly concerning two

Table 1. Growth of internet users between 2007 and 2012 [2].

\begin{tabular}{|c|c|c|c|}
\hline Region & 2007 (millions) & 2012 (millions) & Growth \\
\hline Africa & 34 & 140 & $311 \%$ \\
\hline Asia & 418 & 1017 & $143 \%$ \\
\hline Europe & 322 & 501 & $56 \%$ \\
\hline Middle East & 20 & 77 & $285 \%$ \\
\hline North America & 233 & 273 & $17 \%$ \\
\hline Latin America & 110 & 236 & $115 \%$ \\
\hline Oceania & 19 & 24 & $26 \%$ \\
\hline Worldwide & 1156 & 2268 & $96 \%$ \\
\hline
\end{tabular}
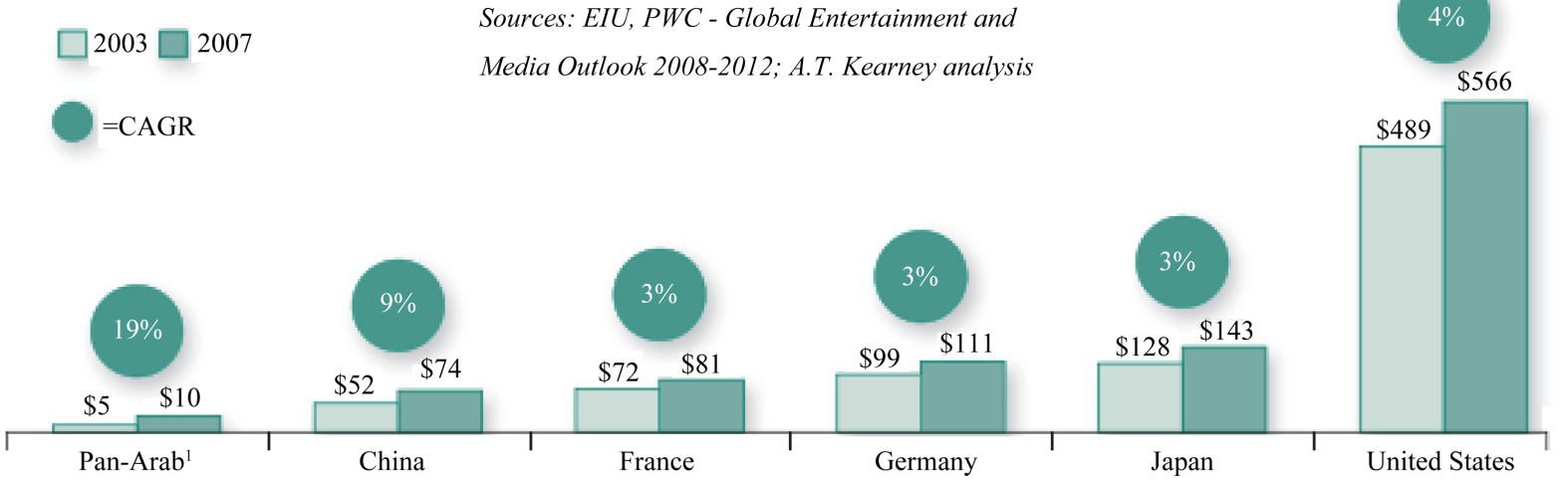

Notes: All monetary amounts in billons of U.S. dollars; CAGR = compound annual growth rate

${ }^{1}$ Algeria, Bahrain, Egypt, Jordan, Kuwait, Lebanon, Libya, Morocco, Oman, Qatar, Syria, Saudi Arabia and the UAE 
sides: website presentation and quality of service. The results showed that the Mawaweel website has the ability to succeed, especially if specific improvements are applied to the quality of service, and to the presentation of its home page.

The remaining sections of this article are organized as follows. Literature review is discussed in Section 2. The Mawaweel website is overviewed in Section 3. Methodology and work schedule is tackled in Section 4. The survey is demonstrated in Section 5 and is discussed in Section 6. Proposed improvements to the website are explained in Section 7. Finally, in Section 8, we conclude our contribution presented in this article and suggest a future work.

\section{Literature Review}

In [5], an analytic hierarchy process was applied to examine the influence of website quality on the performance and success of e-business. The authors explored different quality factors and compared their importance in deciding the preference of websites. Results of their study showed that the top business performance is delivered by the websites with the top quality. The commercial scenarios of the web were investigated in [6]; two main classes of websites were identified: traffic control and destination websites. The former class included search engines, incentive websites and malls (websites comprising a pool of online storefronts). The key role of such websites is to guide customers to destination websites, including: content websites, web storefronts and virtual presence websites. The authors claimed that the marketing purpose is to integrate traffic and destination websites to create and secure recurring visits.

In [7], an assessment of the process of developing e-business models was performed with focus on on-line music and news in Europe. Among the two promising models mentioned in their contribution, was the model combining the making, acquisition and virtual dissemination of media content. The influence of language and culture on the usability of commercial websites was studied in [8]. It was found that the observed usability grew with websites originally written in the users' mother tongue.

The use of information and communication technologies (ICT) as a tool to extend the goals of the music education curriculum was discussed in [9]. This reference encouraged instructors as well as students' to benefit of the diverse musical opportunities presented by ICT. In [10], it was statistically found that the time period spent by students on the website of a particular university module correlates with the students' performance in that module. The educational process in the Irish traditional virtual music community (IrTrad) was investigated in [11]. It was found that YouTube videos encouraged heated conversations tackling the different features of the videos, such as: value, authenticity and helpfulness in teaching and learning.

Recently, there have been remarkable efforts in music technology research in Jordan. In [12], music analysis software were utilized effectively to enhance teaching and learning expressive Arab singing. In [13] [14], a computer toolbox was proposed to improve learning and using Arab woodwinds. The toolbox benefited of a melodic music information retrieval model discussed in [15] [16]. In those contributions, as well as in [17], the particularity of Arab music was considered when proposing tools and models for woodwinds. Such customized research can function as basic building blocks for commercial software serving both the educational and the entertainment industries in the Arab world.

\section{Mawaweel: The Term and the Website}

We clarified the definition of the term Mawaweel in Section 2.1. Then we presented the Mawaweel website and application in Section 2.2.

\subsection{The Term}

The classical/traditional vocal improvisation of the Arab region is called in Arabic: Mawwāl (plural: Mawaweel). It is a non-metric musical form which is usually related to the narrative poetry. It is usually headed by a brief instrumental improvisation as an introductory stage aimed at developing the feeling of "saltanah", or modal ecstasy. In this musical form, the singer shows her/his expertise and talents whereas the instrumentalists give support to her/him. They achieved this by following the singer's lead throughout every improvised phrase, and by summarizing the phrase upon completion. Besides, the instrumentalists insert their own artistic touches on what they follow and recapitulate [18] [19]. The interactivity and liveliness among the improviser, the instrumentalists and 
the audience are amongst the main reasons for which the Mawwāl form gets much impact and admire on listeners.

\subsection{Website}

Mawaweel is a web application that offers an automatic musical accompaniment to Arab sung improvisation, [20]. The website of this application has only one page [4], and it is presented in Figure 2. The page has the following layout: a brief guidance on how to use the application is presented on top, just below the title. The Mawaweel application (as a web applet) is in the middle of the page. And finally, a hyperlink to examples of automatically accompanied improvisations using the Mawaweel application is shown at the bottom of the page, with a brief description of its content.

Using the Mawaweel application, the user may record her/his vocal improvisation before listening to its playback with five different ways of accompaniment. The accompaniment ways provided by the Mawaweel web application are as follows [20]:

1) Heterophonic variation of the improvised melody

The vocal improvisation is accompanied with one instrument playing a heterophonic variation of the vocal melody. i.e. the instrument plays the same melody but with a possible slight modification to the onset and duration of each note. The instrument used in this accompaniment is the qanoun.

2) Structural notes of the improvised score

The vocal melody is accompanied with one instrument performing only the main, or structural, notes of the improvised melody. This way of accompaniment gives both feelings of continuity and variety. Continuity is achieved because the structural notes (usually long or extreme) are always performed, and variety is made because other less important notes are substituted with silence or prolonged main notes. The instrument used in this accompaniment is the violin.

\section{3) Imitation}

Imitation may be described as a full or partial recurrence of a melody or motivic idea. This way of accompaniment is best used to fill up silences among the different vocal figures, or sentences. In the Mawaweel application, the imitation may be a shrunk or stretched variety of the performed vocal figure. It may be a full repetition of it or a truncated version. Moreover, Imitation may start soon after the end of the vocal figure, or a bit before so this gives a feeling of continuity".

4) Harmonic accompaniment

The vocal improvisation is accompanied with piano chords. Three main chords are used with their inversions, and utilized according to a formula introduced from flamenco music. This is because flamenco has Arab roots and share many things in common with Arab music, such as some scales, intervals, rhythms and ornamentation [21].

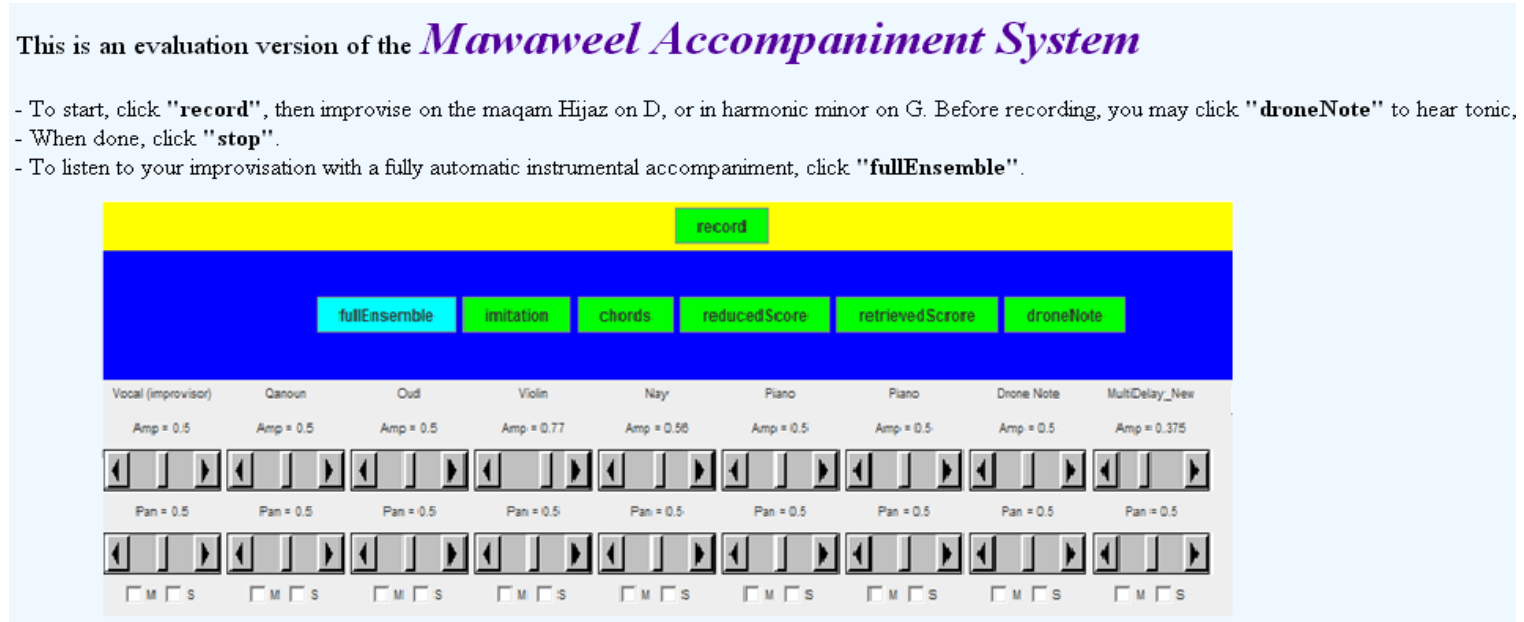

not in a mood to improvise, but wanna listen?!,

Click on the following link to listen to examples of automatically accompanied vocal improvisations: Mawaweel uploaded to SoundCloud

Figure 2. Snapshot of the homepage of Mawaweel website [4]. 
5) Full ensemble

This way of accompaniment combines all the previous ways of accompaniment and forms one comprehensive way performed by several instruments: qanoun, violin, oud, Nay and piano. The full ensemble accompaniment is considered the default way of accompaniment.

\section{Methodology and Work Schedule}

The main approaches followed in this research project were the statistical and analytical. Yet, the work included tasks within the descriptive and comparative approaches. The project had four stages; the first was inceptive stage in which the Mawaweel website was overviewed. In the second stage, a survey examining the satisfaction of the website visitors was prepared and disseminated to potential users. The survey results were discussed and improvements to the website were proposed in the third stage. In the last stage, the research outcome was documented then published. The approximate durations for the four stages were two weeks, two months, three months and five months, respectively. The stages, tasks, approaches and durations are all depicted in Table 2.

\section{The Survey}

The Mawaweel website was introduced, thoroughly, as an entertainment site to a sample of potential users before disseminating a copy of the survey to each of them. The entire number of respondents was 22 from both sexes and from different ages and backgrounds. The survey included ten points tackling the presentation and the quality of the website. Four points measured the presentation of the contents of the website, and five points measured the quality and usefulness of the website. The last point measured the general opinions on the experience of visiting the Mawaweel website.

Every respondent was requested to fill a three-part form in which she/he rates several aspects of the website. For every aspect, the respondent chooses one out of five available rates: strongly agree, agree, undecided, disagree and strongly disagree. Each of the next three tables shows one or more aspects of the Mawaweel website with the rate of each aspect. In every point of each table, a certain aspect is presented together with the ratio of respondents selecting each rate, and the average rate of that particular aspect. The average rate signifies the general rate of an aspect, and is calculated like this: The rate given by every respondent is translated to a numerical value as follows: strongly agree is translated to $100 \%$, agree to $75 \%$, undecided to $50 \%$, disagree to $25 \%$ and strongly disagree to $0 \%$. The numerical values of the rates gathered from all respondents are then combined and divided by the overall number of respondents to get the average rate.

Table 3 presents the respondents' views on the presentation of the contents of the website: domain name, loading time, design \& interactivity and finally the instructing steps to get the musical accompaniment. For every aspect, the table displays the ratio of respondents electing each of the five different rates, and the average rate of that aspect. The mean and the standard deviation of average rates are also presented in the table.

Table 4 presents the respondents' views on five elements measuring the quality and usefulness of the website. The elements tackles the following aspects: the quality of the final product (improvisation with musical accompaniment), the diversity of accompaniment options, the possibility to save and retrieve the accompaniment and its settings, the possibility to use the website for educational purposes, and finally, the comprehensiveness of website usability to everybody. Every element is displayed with its average rate and the ratio of respondents electing each of the five different rates.

\section{Table 2. Tasks, approaches and duration for each stage of this project.}

\begin{tabular}{|c|c|c|c|c|}
\hline N. & Stage & Task & Approach & Duration \\
\hline 1 & Inceptive stage & - $\quad$ Overviewing Mawaweel website: presentation \& quality of service. & Descriptive & Two weeks \\
\hline 2 & $\begin{array}{c}\text { Survey } \\
\text { handling }\end{array}$ & $\begin{array}{l}\text { - Preparing a survey examining visitors' satisfaction. } \\
\text { - } \quad \text { Disseminating the survey, then collecting results. }\end{array}$ & Statistical & Two months \\
\hline 3 & $\begin{array}{l}\text { Analysis \& } \\
\text { improvement }\end{array}$ & $\begin{array}{l}\text { - Analyzing and discussing obtained results. } \\
\text { - Proposing improvements to the website based on: analysis results \& } \\
\text { comparison with other websites. }\end{array}$ & $\begin{array}{l}\text { Analytical\& } \\
\text { comparative }\end{array}$ & Three months \\
\hline 4 & Documentation & $\begin{array}{l}\text { - Documenting and publishing this research experience in conferences, } \\
\text { journals and/or press. }\end{array}$ & Descriptive & Five months \\
\hline
\end{tabular}


Table 3. Respondents' opinions on the presentation of the contents of the website.

\begin{tabular}{|c|c|c|c|c|c|c|c|}
\hline \multirow[b]{2}{*}{ N. } & \multirow[b]{2}{*}{ Aspect } & \multicolumn{5}{|c|}{ Rate } & \multirow[b]{2}{*}{ Averag } \\
\hline & & $\begin{array}{l}\text { Strongly } \\
\text { agree }\end{array}$ & Agree & Neutral & Disagree & $\begin{array}{l}\text { Strongly } \\
\text { disagree }\end{array}$ & \\
\hline 1 & $\begin{array}{l}\text { The domain name "mawaweel.com" is easy to remember } \\
\text { and memorize }\end{array}$ & $59 \%$ & $32 \%$ & $0 \%$ & $4.5 \%$ & $4.5 \%$ & $86.38 \%$ \\
\hline 2 & The website does not require a long time to load. & $36.5 \%$ & $18.5 \%$ & $18 \%$ & $18 \%$ & $9 \%$ & $63.88 \%$ \\
\hline 3 & The website design is clear, attractive and user friendly & $13.5 \%$ & $18 \%$ & $32 \%$ & $25 \%$ & $11.5 \%$ & $49.25 \%$ \\
\hline 4 & $\begin{array}{l}\text { The presentation of the steps required to get the musical } \\
\text { accompaniment is clear and easy }\end{array}$ & $31.5 \%$ & $50 \%$ & $9.5 \%$ & $0 \%$ & $9 \%$ & $73.75 \%$ \\
\hline \multicolumn{2}{|c|}{ Mean of average rates $\rightarrow$} & & & & & & $68.32 \%$ \\
\hline \multicolumn{2}{|c|}{ Standard deviation of average rates $\rightarrow$} & & & & & & $15.70 \%$ \\
\hline
\end{tabular}

Table 4. Respondents' opinions on the quality and usefulness of the website.

\begin{tabular}{|c|c|c|c|c|c|c|c|}
\hline \multirow[b]{2}{*}{$\mathbf{N}$. } & \multirow[b]{2}{*}{ Aspect } & \multicolumn{5}{|c|}{ Rate } & \multirow[b]{2}{*}{ Average } \\
\hline & & $\begin{array}{l}\text { Strongly } \\
\text { agree }\end{array}$ & Agree & Neutral & Disagree & $\begin{array}{l}\text { Strongly } \\
\text { disagree }\end{array}$ & \\
\hline 1 & $\begin{array}{l}\text { From the perspectives of musical composition and sound } \\
\text { recording \& reproduction, the final product (improvisation } \\
\text { with musical accompaniment) is of a high quality }\end{array}$ & $7 \%$ & $29 \%$ & $34.5 \%$ & $13.5 \%$ & $16 \%$ & $49.38 \%$ \\
\hline 2 & $\begin{array}{l}\text { The website offers a broad range of different } \\
\text { accompaniment ways }\end{array}$ & $9 \%$ & $22 \%$ & $27.5 \%$ & $14 \%$ & $27.5 \%$ & $42.75 \%$ \\
\hline 3 & $\begin{array}{l}\text { It is possible to save and retrieve the improvisation, } \\
\text { accompaniment or the settings of the mixer. }\end{array}$ & $9 \%$ & $0 \%$ & $9 \%$ & $36.5 \%$ & $45.5 \%$ & $22.63 \%$ \\
\hline 4 & I can use this website to improve my singing skills. & $32 \%$ & $27.5 \%$ & $27 \%$ & $9 \%$ & $4.5 \%$ & $68.38 \%$ \\
\hline 5 & $\begin{array}{l}\text { Anyone can use this website regardless of musical skills or } \\
\text { sound range }\end{array}$ & $19 \%$ & $53 \%$ & $9 \%$ & $19 \%$ & $0 \%$ & $68.00 \%$ \\
\hline \multicolumn{2}{|c|}{ Mean of average rates $\rightarrow$} & & & & & & $50.23 \%$ \\
\hline \multicolumn{2}{|c|}{ Standard deviation of average rates $\rightarrow$} & & & & & & $19.13 \%$ \\
\hline
\end{tabular}

Table 5 presents the respondents' overall views on their experience of visiting the Mawaweel website. The table displays the average rate and the ratio of respondents electing each of the five different rates. Statistical results presented in these three tables are discussed in the next section.

\section{Discussion}

The statistics presented in the previous tables reflect a mere satisfaction on some aspects and an obvious dissatisfaction on some other aspects. In Table 3 showing the respondents' opinions on the presentation of the website contents, the mean of average rates is $68.32 \%$. This might be considered as a mere satisfaction on the general presentation of the website. The standard deviation of those rates is $15.70 \%$. This reveals a sort of inhomogeneity in the value of the different aspects of the presentation. For example, the votes clearly tell that selecting the word "mawaweel" for the domain name is a successful choice, but the votes, on the other hand, express dissatisfaction on the design and user-friendliness of the website.

In Table 4 which shows the respondents' opinions on the usefulness and quality of the Mawaweel website, the statistics show an expanded inhomogeneity in the quality of the different services delivered by the website. Although the mean of average rates is $50.23 \%$, this ratio is not representative because the standard deviation is high: $19.13 \%$. This means that the different votes are scattered far away from the mean. For example, while the majority of the respondents considered the website as a useful way to improve singing skills with an average rate of $68.38 \%$, only $22.63 \%$ of the votes went for the ability of the website to save and retrieve the accompaniment and the settings of the mixer. The latter ratio is not shocking indeed, because this service, save \& retrieve, is not actuality supported by this version of the application. So nobody can save or retrieve unless he/she 
Table 5. Respondents' general opinions on the experience of visiting the Mawaweel website.

\begin{tabular}{llccccc}
\hline \multicolumn{1}{c}{ Aspect } & \multicolumn{5}{c}{ Rate } \\
\cline { 3 - 5 } N. & $\begin{array}{c}\text { Strongly } \\
\text { agree }\end{array}$ & Agree & Neutral & Disagree & $\begin{array}{c}\text { Strongly } \\
\text { disagree }\end{array}$ & Average \\
\hline $\begin{array}{l}\text { I felt satisfied with my experience of visiting the Mawaweel } \\
\text { website for automatic accompaniment of Arab vocal } \\
\text { improvisation }\end{array}$ & $27 \%$ & $55 \%$ & $9 \%$ & $9 \%$ & $0 \%$ & $75 \%$ \\
\hline
\end{tabular}

performs a workaround such as recording the sound produced by the computer's sound card. Indeed, this is not practical at all.

Table 5 has a special importance as it seeks the respondents' general opinions after visiting the Mawaweel website. It is promising that the average vote is $75 \%$. This expresses a general satisfaction, and assures the importance of such websites. This also tells that the respondents' strict critics on some aspects of the previous tables are targeted at improving the presentation and services of the website rather than criticizing the whole idea.

\section{Proposed Improvements to the Website}

In order to increase the traffic and thus improving the commercial value of the Mawaweel website, we propose improvements to the aspects that gain a low average rate in the above-discussed survey. Precisely, a rate below $50 \%$. Four aspects fall within this category, as follows:

\subsection{Variety of Accompaniment Ways}

Line in survey form: The website offers a broad range of different accompaniment way.

The website already offers five accompaniment types: full ensemble, imitation, chords, reduced score and retrieved score. Such low average vote for this line (42.75\%) tells explicitly that the accompaniment ways are neither sufficient nor satisfying. This may have more than one explanation. In the following lines, we present four explanations for the dissatisfaction together with ideas to achieve satisfaction:

- Lack of guidance or visual illustration in the website; so some of the respondents did not know how to use the web application and get different accompaniment types. Accordingly, it is important to provide the users with written guidance or possibly illustrating videos.

- It is possible that the respondents, or some of them, did not understand the names of the different accompaniment ways. Therefore, it is important to replace the difficult technical terminology with easier names that are are simpler and well-understood by common people regardless of their musical backgrounds.

- The musical quality of some compositional ways is not satisfying. So although there are five ways available, but some of them is not satisfying. In view of this, it is necessary to improve the design of the compositional algorithms in order to ameliorate the accompaniment.

- In the available version of the web application, the user is forced to improvise in one particular maqam, the hijazmaqam. Moreover, the user has no control on the choice of the accompanying musical instruments. Therefore, it is required to expand the choice of the maqam of improvisation, and also to allow the user to choose among the different instruments.

\subsection{Quality of the Final Product}

Line in survey form: From the perspectives of musical composition and sound recording \& reproduction, the final product (improvisation with musical accompaniment) is of a high quality.

This line has an average vote of $49.38 \%$, and thus reflects respondents' dissatisfaction. A possible explanation for this discontent may be the structure of the proposed accompaniment tracks. So let us consider the melodic accompaniment as example. The web application offers three different melodic accompaniment choices: the imitation, reduced score and the retrieved score. As mentioned in [22], all the three choices are different representations of the musical score (notation) of the vocal improvisation. I.e. there has not been a striking or creative effort from the perspective of music composition. In light of this, we emphasize on a particular point mentioned in the previous subsection, which is the necessity of improving the compositional algorithms of all accompani- 
ment ways whether melodic or harmonic. Indeed, interesting examples on the harmonization and poliphonization of Arab melodies can be found in [23].

Moreover, we find it important to design an algorithm to handle the instrumentation in a better way. In the current version of the application, the imitation is always performed by the oud, and the retrieved score is always performed by qanoun. Thus, there should be a more sophisticated algorithm that allows for a flexible choice of instruments, just like in real life accompaniment. As for improving the product from the perspective of sound recording and reproduction, we see it advantageous to provide the web application with better audio samples as the current ones are not of a high quality.

\subsection{Ability of Saving and Retrieving}

Line in survey form: It is possible to save and retrieve the improvisation, accompaniment or the settings of the mixer.

This line has an average vote of $22.63 \%$, and this is expected because the services of saving and retrieving the improvisation and accompaniment are not available in the current version of this application. The same applies to the service of saving the settings of the mixer. The user has to perform a workaround in order to record his improvisation or snapshot the mixer's settings. Providing these services can expand the usability of this website and increase the number of users, especially if the users get the ability to share their accompanied improvisations with others on social networks. Such services will require having a user account system in the website. i.e. more effort and cost, but it will—for sure—increase the value of the website. Indeed, common talent distribution and sharing websites such as YouTubeand SoundCloudhave user account systems [24] [25].

\subsection{Website Design}

Line in survey form: The website design is clear, attractive and user friendly.

The average vote of this line is $49.25 \%$. This exposes a weakness in the website design. In this subsection, we attempt to clarify the weakness points of the design of the Mawaweel website, and also to suggest ideas toward an improved design.

A snapshot of the homepage of the Mawaweel website is shown in Figure 2 (see Section 3). Let us discuss four main features of the website design: font, colors, click-buttons and language. As appears in the figure, the website uses a diversity of font sizes, colors and many click-buttons. According to [26], using lots of colors, fonts and click-buttons poisons the website and causes an information overload. So, it is necessary to keep the homepage as simple as possible. This is especially because visitors are not willing to spend more than four seconds to discover the type of service offered by the website [27].

Sometimes, it is necessary to have several options or choices, and thus many click-buttons. For example, there are five different choices for the accompaniment way in the Mawaweel website. In this case, having one dropdown list can be a better alternative than having five click-buttons. To better explain the idea of the drop-down list, let us consider the example shown in Figure 3. This example is taken from a music education website [28], and the title of the drop-down list is "topics". Once the user moves the cursor to this button, the drop-down list appears with all possible topics: chords, intervals, key signatures, etc.

Although the Mawaweel website provides a service targeted mainly at the Arab region, the website is only available in English. This is a drawback that can be solved by introducing bilingualism to the website. An
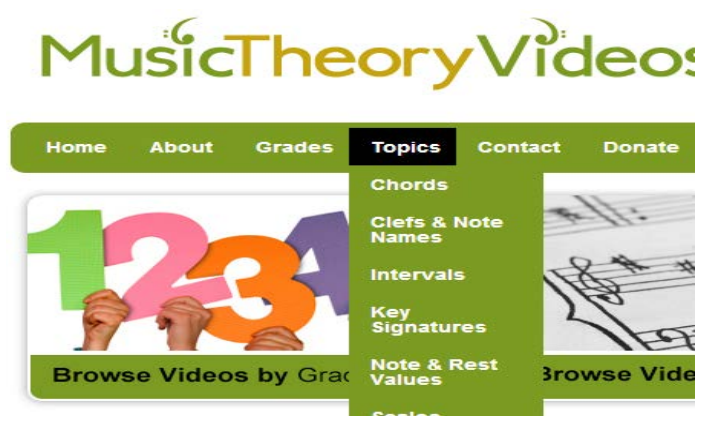

Figure 3. Example of a drop-down list [28]. 


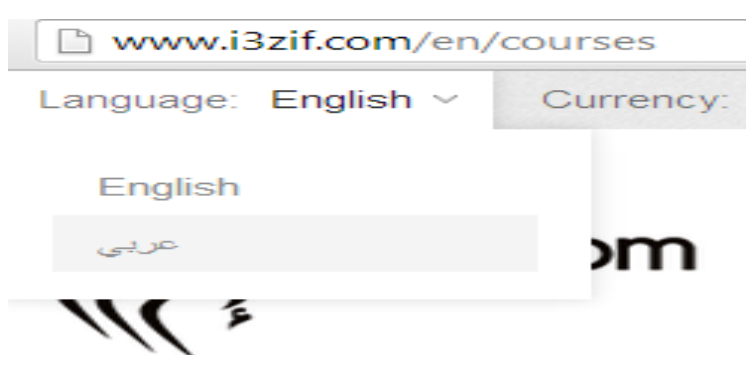

Figure 4. Example of a language drop-down list [29].

example of allowing bilingualism in Arab-targeted music websites is shown in Figure 4. It shows the language drop-down list of awebsite [29]. The menu allows the user to choose between two languages: Arabic and English.

\section{Conclusion and Future Work}

This contribution was targeted at driving more traffic and thus improving the significance of the Mawaweel website, which was chosen as an example of websites delivering automatic musical accompaniment to Arab vocal performance. We handled a survey to study users' opinions in regard to quality of service and website presentation. Results confirmed the ability of the website to make success, mainly if particular enhancements are applied, such as: improving the compositional algorithms of the Mawaweel application, ameliorating the visual guidance and illustration of the website, proposing an Arabic version of the home page and allowing sharing, saving and retrieving the accompanied performance. Future work can include applying similar studies and approaches to websites providing music composition games as web services.

\section{References}

[1] Nasr, V. (2013) Business, Not as Usual. Finance \& Development, 50, 26-29.

[2] Pingdom (2012) World Internet Population Has Doubled in the Last 5 Years. Tech Blog [Web Log]. http://royal.pingdom.com/2012/04/19/world-internet-population-has-doubled-in-the-last-5-years/

[3] Kearney, A.T. (2009) Middle East Media on the Move: An Emerging Growth Industry in a Pivotal Region. http://www.atkearney.com/documents/10192/4095877b-119c-492b-a236-219098f229df

[4] (2013) Mawaweel: Web Applet for Automatic Accompaniment to Arab Vocal Improvisation "Mawwāl”. http://www.mawaweel.com

[5] Lee, Y. and Kozar, K. (2006) Investigating the Effect of Website Quality on e-Business Success: An Analytic Hierarchy Process (AHP) Approach. Decision Support Systems, 42, 1383-1401. http://dx.doi.org/10.1016/j.dss.2005.11.005

[6] Hoffman, D., Novak, T. and Chatterjee, P. (1995) Commercial Scenarios for the Web: Opportunities and Challenges. Journal of Computer-Mediated Communication, $\mathbf{1}$.

[7] Swatman, P.M.C., Krueger, C. and van der Beek, K. (2006) The Changing Digital Content Landscape: An Evaluation of e-Business Model Development in European Online News and Music. Internet Research, 16, 53-80. http://www.emeraldinsight.com/doi/abs/10.1108/10662240610642541 http://dx.doi.org/10.1108/10662240610642541

[8] Nantel, J. and Glase, E. (2008) The Impact of Language and Culture on Perceived Website Usability. Journal of Engineering and Technology Management, 25, 112-122. http://dx.doi.org/10.1016/j.jengtecman.2008.01.005

[9] Savage, J. (2005) Information Communication Technologies as a Tool for Re-Imagining Music Education in the 21st Century. International Journal of Education \& the Arts, 6. http://www.ijea.org/v6n2/

[10] Korkofingas, C. and Macri, J. (2013) Does Time Spent Online Have an Influence on Student Performance? Evidence for a Large Business Studies Class. Journal of University Teaching \& Learning Practice, 10.

[11] Waldron, J. and Veblen, K. (2008) The Medium Is the Message: Cyberspace, Community, and Music Learning in the Irish Traditional Music Virtual Community. Journal of Music, Technology \& Education, 1, 99-111.

[12] Al-Ghawanmeh, F., Haddad, R. and Al-Ghawanmeh, M. (2014) Proposing a Process for Using Music Analysis Software to Improve Teaching Authentic Arab Singing and Ornamenting. International Journal of Humanities and Social Science. 
[13] Al-Ghawanmeh, F., Al-Ghawanmeh, M. and Haddad, R. (2009) Appliance of Music Information Retrieval System for Arabian Woodwinds in E-Learning and Music Education. Proceedings of the International Computer Music Conference, Montréal, 16-21 August 2009, 17-20.

[14] Haddad, R., Al-Ghawanmeh, F. and Al-Ghawanmeh, M. (2010) Educational Tools Based on MIR System for Arabian Woodwinds. Journal of Music, Technology and Education, 3, 31-45. http://dx.doi.org/10.1386/jmte.3.1.31_1

[15] Al-Taee, M., Al-Rawi, M. and Al-Ghawanmeh, F. (2008) Time-Frequency Analysis of the Arabian Flute (Nay) Tone Applied to Automatic Music Transcription. Proceedings of the 6th ACS/IEEE International Computer Systems and Applications, Doha, 31 March-4 April 2008, 891-894. http://dx.doi.org/10.1109/AICCSA.2008.4493636

[16] Al-Taee, M., Al-Ghawanmeh, M., Al-Ghawanmeh, F. and Omar, B. (2009) Analysis and Pattern Recognition of Arabian Woodwind Musical Tones Applied to Query-by-Playing Information Retrieval. Proceedings of the International Conference of Computer Science and Engineering, ICCSE-59, World Congress on Engineering, WCE 2009, London, 1-3 July 2009.

[17] Al-Ghawanmeh, F., Jafar, I., Al-Taee, M., Al-Ghawanmeh, M. and Muhsin, Z. (2011) Development of Improved Automatic Music Transcription System for the Arabian Flute (Nay). Proceedings of the 8th International Multi-Conference on Systems, Signals and Devices (SSD-11), Sousse, 22-25 March 2011, 1-6. http://dx.doi.org/10.1109/SSD.2011.5993561.

[18] Racy, A.J. (1998) Improvisation, Ecstasy, and Performance Dynamics in Arabic Music. In: Nettle, B. and Russell, M., Eds., In the Course of Performance: Studies in the World of Musical Improvisation, Chicago University Press, Chicago, 95-112.

[19] Arabic Musical Forms (2007) In Maqam World. www.maqamworld.com

[20] Al-Ghawanmeh, F. (2013) Automatic Accompaniment to Arab Vocal Improvisation “Mawwāl”. Unpublished Master’s Thesis, New York University, New York.

[21] Chuse, L. (2003) Cantaoras: Music, Gender and Identity in Flamenco Song. Routledge, New York.

[22] Al-Ghawanmeh, F., Al-Ghawanmeh, M. and Obeidat, N. (2014) Toward an Improved Automatic Melodic Accompaniment to Arab Vocal Improvisation, Mawwāl. Proceedings of the 9th Conference on Interdisciplinary MusicologyCIM14, Berlin, 4-6 December 2014, 397-400.

[23] Al-Momani, M. and Al-Ghawanmeh, F. (2015) The Impact of an Arab-Influenced Piano Curriculum on Students with an Arab Background. International Education Studies, Canadian Center of Science and Education, Toronto.

[24] Strickland, J. (2007) How YouTube Works. http://money.howstuffworks.com/youtube3.htm

[25] What's the Difference between Each Subscription Level? http://help.soundcloud.com/customer/portal/articles/247820-what-s-the-difference-between-each-subscription-level-

[26] Winchel, W. (2012) 5 Ways to Get Your Website Design Back into Shape. Kunocreative Blog (Web Log). http://www.kunocreative.com/blog/bid/73640/5-Ways-to-Get-Your-Website-Design-Back-into-Shape

[27] Scaglione, J. (2012) Usability Testing: Why Great Design Is Only Half the Battle. Designmodo (Web Log). http://designmodo.com/usability-testing/

[28] Music Teacher (2014) Music Theory Videos. http://www.musictheoryvideos.com/

[29] I3zif.com (2013) The Oud Is the Most Popular Arabic Musical Instrument. http://www.i3zif.com/en/ 
Scientific Research Publishing (SCIRP) is one of the largest Open Access journal publishers. It is currently publishing more than 200 open access, online, peer-reviewed journals covering a wide range of academic disciplines. SCIRP serves the worldwide academic communities and contributes to the progress and application of science with its publication.

Other selected journals from SCIRP are listed as below. Submit your manuscript to us via either submit@scirp.org or Online Submission Portal.
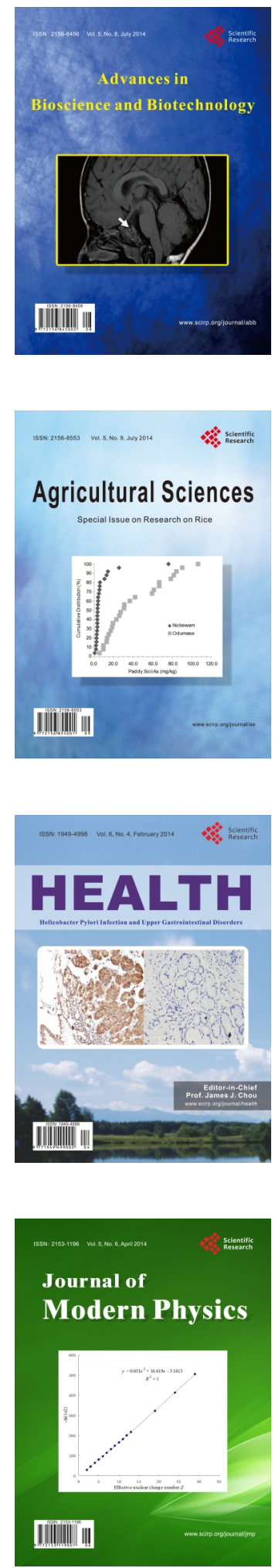
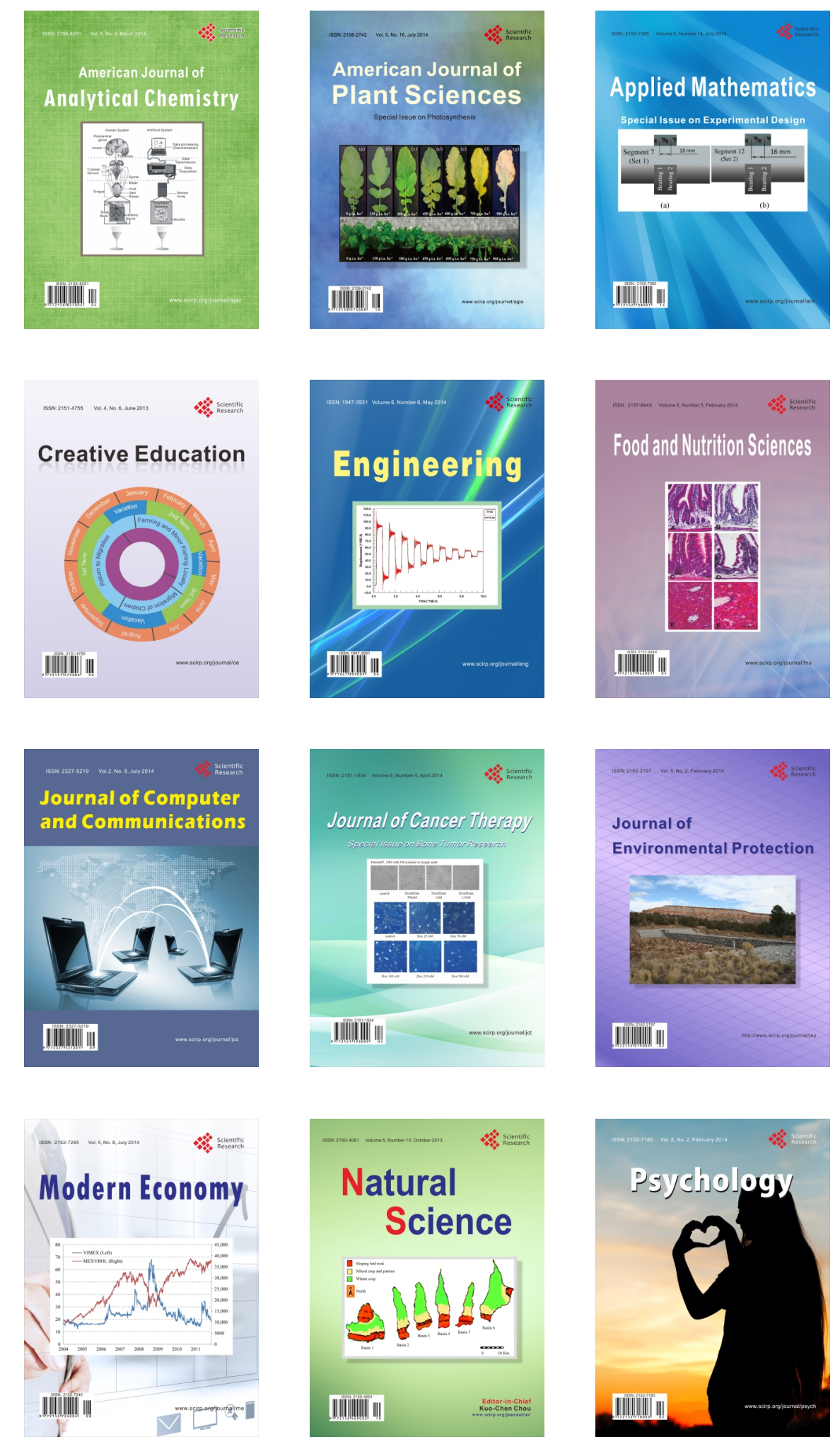